\title{
Fatigue Characteristics of Electroformed Sheets with and without Iron Backing
}

\author{
By Harry K. Herschman and Carroll Thomas ${ }^{1}$
}

\begin{abstract}
The flexural fatigue properties were determined for electroformed sheets of iron-nicke. and iron-nickel-chromium, and of plates composed of electroformed iron nickel sheets bonded with solder or a plastic adhesive to open-hearth iron. The fatigue limit of the iron-nickel composite was decreased when a thin deposit of chromium was applied to the nickel face. Heating the iron-nickel-chromium sheets at $260^{\circ} \mathrm{C}\left(500^{\circ} \mathrm{F}\right)$ before machining improved their fatigue properties. Apparent further beneficial effects resulted by heating after machining. The fatigue limits of the plates bonded with the plastic adhesive were significantly higher than those joined by soldering. Two brushed coats of the plastic adhesive applied to the mating surfaces of the composite layers of the plates appeared somewhat more favorable to higher fatigue limits than a combination one brushed and one sprayed coat procedure.
\end{abstract}

\section{Introduction}

Structures or segments of structures frequently are prepared by bonding a metal or alloy having certain properties to another metal or nonmetallic material having wholly different properties. Such composites usually will have a combination of desired characteristics that no single material possesses. The joining of the constituent parts may be accomplished by various means, such as soldering, fusion welding, or adhesive cementing. Many of the intaglio printing plates used at the Bureau of Engraving and Printing are prepared by bonding an electroformed face shell composed of a layer of iron and a layer of nickel to a backing of openhearth iron. Previously, soldering supplemented by spot welding was employed for joining these two segments. Because of failures in the solderbonded plates, plastic adhesives have been replacing this method for securing the required bond between the electrolytic shell and the iron back.

The manner of affixing a plate on the printingpress bed causes a slight convexity of the printing surface when the plate is not in operation. The loading of the plate as it passes under the roll while printing tends to flatten the printing surface, resulting in a repeated flexing of the plate. It is this flexing action that causes failure by fatigue in

$1{ }^{1}$ Foreman, Electrolytic Section, Bureau of Engraving and Printing. some of the constituent layers of the electrolytically "built-up" shell, which is the portion of the plate subjected to the maximum tensile stresses. This has occurred particularly in the plates bonded with tin-lead solders. A number of factors, such as residual stress in the electroformed shell, the nature of the bonding agent, and brittle constituents at the interface of the iron layer of the electroplated shell and the solder may influence the fatigue properties of these composite plates. In order to ascertain how these factors affect the fatigue characteristics of the electroformed shells alone and as bonded to fabricated iron backs, their behavior under controlled fatigue stressing was investigated.

A review of the literature dealing with the fatigue properties of electroformed metals and of structures bonded with plastic adhesives or solders revealed only scant information on these subjects. A Navy report ${ }^{2}$ on the mechanical properties of structures bonded with a plastic adhesive stated that a magnesium assembly joined with this adhesive still carried 100 percent of the design load after $10 \times 10^{6}$ cycles, whereas a similar structure assembled with rivets failed in $3 \times 10^{6}$ cycles. Similar results were reported by Westbrook $^{3}$ for

\footnotetext{
2 Naval Air Experimental Station, Philadelphia Report (April 1, 1944).

3 Adhesives for gluing th in metal sheets, F. A. Westbrook, Steel Processing 34, 26 (Jan. 1948).
} 
lap joints secured both by riveting and adhesive cementing respectively. Grover and Jackson ${ }^{4}$ found that lap joints of magnesium sheet secured with "Cycleweld" were stronger both statically and in fatigue than joints made by riveting and spot welding and were comparable in these resspects with "Heliare" welded joints. However, data showing the comparative fatigue properties of joints bonded with solders and adhesive cements respectively, do not appear to be available.

Most of the reports discussing the fatigue properties of electroplated metals consider them in connection with their influence as a coating on other metals or alloys. An unpublished report of Oberg and Powers ${ }^{5}$ indicates that the flexural fatigue limit of 0.1-in. sheets of electroformed nickel "as deposited" is about $43,000 \mathrm{lb} / \mathrm{in}^{2}$. Heating this sheet at $400^{\circ} \mathrm{F}$ for $2 \mathrm{hr}$ increased the fatigue limit to $46,000 \mathrm{lb} / \mathrm{in}^{2}$.

\section{Materials and Specimens}

The test specimens used in the first phase of

\footnotetext{
4 The fatigue strength of lap joints in some magnesium sheet alloys, H. J. Grover and L. R. Jackson, ASTM Tech. Pub. No. 72 (Symposium on testing parts and assemblies.)

${ }^{5}$ Private communication, T. T. Oberg and J. B. Powers, Wright, Patterson Air Force Base, Dayton, Ohio.
}
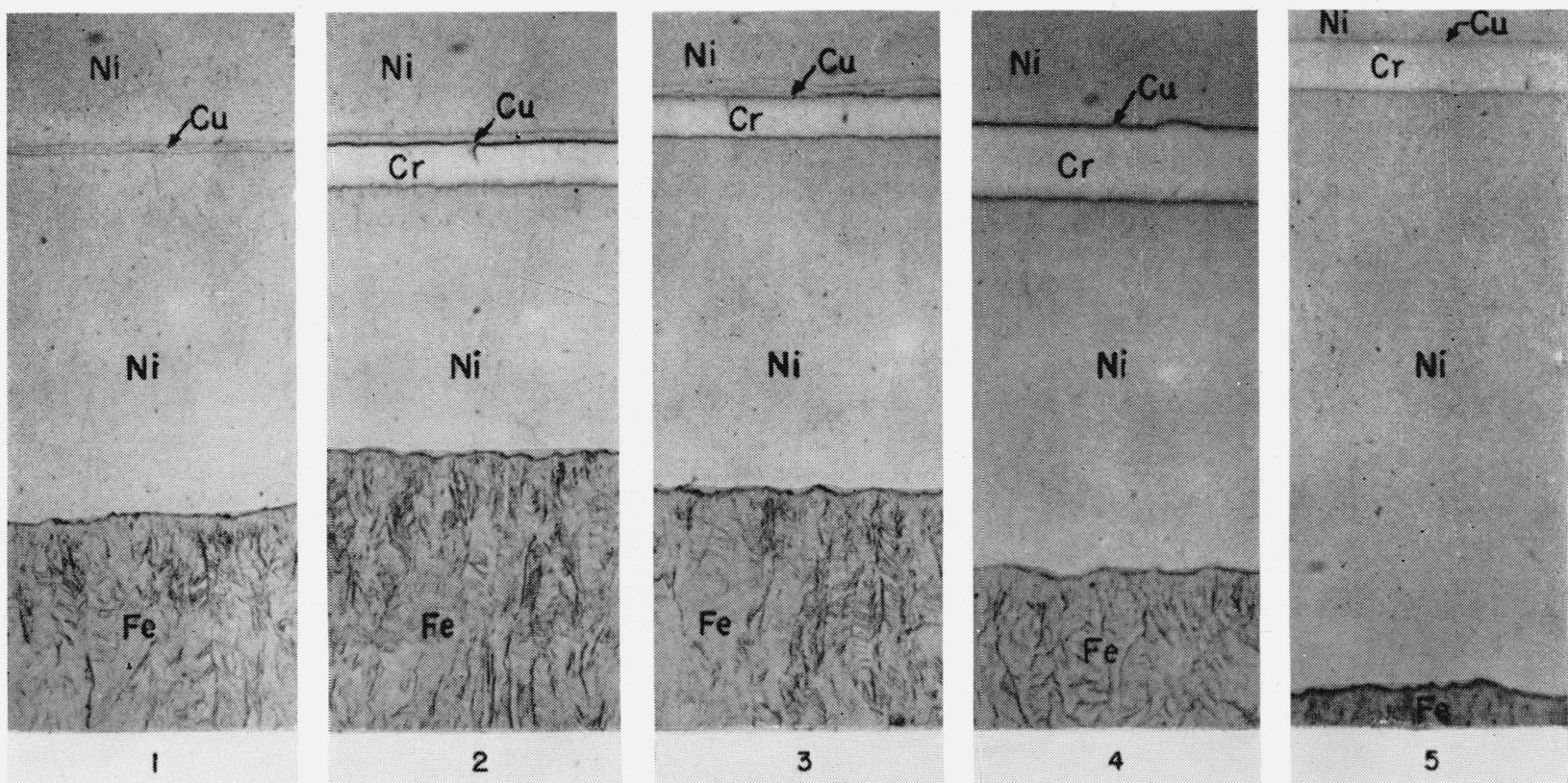

FIgURE 1. Sections of fatigue specimens of electroformed sheet showing thickness of the nickel and chromium layers respectively.

The layers of copper and nickel indicated at the top of the micrographs were applied to the metallographic specimens to prevent rounding of the adiacent edges of the specimens during polishing. Number designations of micrographs correspond to sheet numbers in table $1 . \quad$ Etched in 5 percent picral. Magnification $\times 500$. 

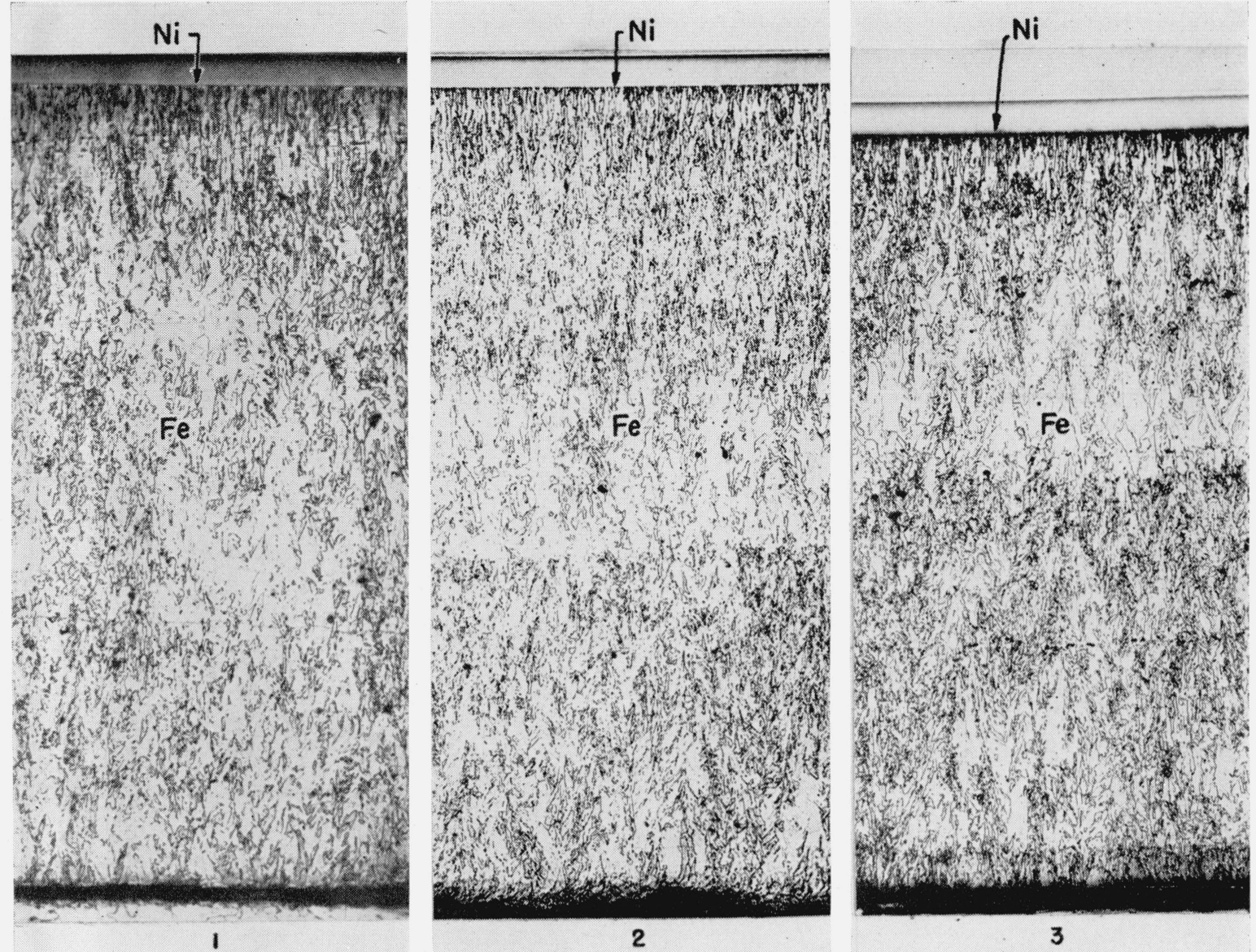

FIguRE 2. Sections of fatigue specimens of printing plate composed of an electroformed portion of a layer each of iron and nickel bonded to a backing of open hearth iron.

Number designations of micrographs correspond to plate numbers in table 2. Magnification $\times 50$.

rinsed with water immediately prior to immersing the sheet in the chromium plating bath.

The conditions of plating and the compositions for the different electroplating baths employed were as follows:

(1) Nickel bath

$$
\begin{array}{lr}
\mathrm{NiSO}_{4} \cdot 7 \mathrm{H}_{2} \mathrm{O} \ldots \ldots & 200 \mathrm{~g} / \text { liter } \\
\mathrm{NiCl}_{2} \cdot 6 \mathrm{H}_{2} \mathrm{O} \ldots \ldots \ldots & 40 \mathrm{~g} / \text { liter } \\
\mathrm{H}_{3} \mathrm{BO}_{3} \ldots \ldots \ldots & 20 \mathrm{~g} / \text { liter }
\end{array}
$$

Current density $=2 \mathrm{amp} / \mathrm{square}$ decimeter; $\mathrm{pH}=5.1$;

Temperature $=40^{\circ} \mathrm{C}$;

Time of plating $=6 \mathrm{hr}$.

(2) Iron bath

$$
\begin{aligned}
& \mathrm{FeCl}_{2} \cdot 4 \mathrm{H}_{2} \mathrm{O} \\
& 450 \mathrm{~g} \text {-liter } \\
& \mathrm{CaCl}_{2} \\
& 200 \mathrm{~g} \text { /liter }
\end{aligned}
$$

Current density $=7$ amp/square decimeter; $\mathrm{pH}=1.0$;

Temperature $=95^{\circ} \mathrm{C}$;
Time of plating $=36 \mathrm{hr}$.

(3) Chromium bath

$$
\begin{array}{ll}
\mathrm{CrO}_{3} \ldots \ldots & 250 \mathrm{~g} / \text { liter } \\
\mathrm{H}_{2} \mathrm{SO}_{4 \ldots \ldots} \ldots \ldots & 2.5 \mathrm{~g} / \text { liter }
\end{array}
$$

Current density $=27 \mathrm{amp} / \mathrm{square}$ decimeter;

Temperature $=50^{\circ} \mathrm{C}$;

Time of plating $=40 \mathrm{~min}$.

The thickness of each component layer of the electroformed composites, tested as such, are listed in table 1. The test specimens prepared from this sheet material were of the form and dimensions shown in figure 3 . A number of the specimens prepared from the composite sheets 2 and 3 (table 1) (Numbers 2B and $3 \mathrm{~A}$, table 1) were tinned at $260^{\circ} \mathrm{C}\left(500^{\circ} \mathrm{F}\right)$ on the iron face in some cases and others (number $2 \mathrm{~A}$, table 1) were heated at this temperature without tinning. The edges of the specimens within their gage length were polished with $3 / 0$ fine emery paper to remove 
surface irregularities that might serve as centers of stress concentration and thereby act as nuclei for fatigue failures.

TABLE 1. Fatigue limits of electroformed composite sheets of iron-nickel and iron-nickel-chromium

\begin{tabular}{|c|c|c|c|c|c|c|}
\hline \multirow{2}{*}{$\begin{array}{l}\text { Sheet } \\
\text { No. }\end{array}$} & \multirow{2}{*}{$\begin{array}{l}\text { Electroformed } \\
\text { of layers of }\end{array}$} & \multicolumn{3}{|c|}{ Thickness of layer a } & \multirow{2}{*}{ Treatment } & \multirow{2}{*}{$\begin{array}{c}\text { Fatigue } \\
\text { limit } \\
\left(10^{7}\right. \\
\text { cycles })\end{array}$} \\
\hline & & Iron & Nickel & $\begin{array}{l}\text { Chro- } \\
\text { mium }\end{array}$ & & \\
\hline 1 & Jron-nickel & In. & In. & In. & "As deposited" & lb/in..$^{2}$ \\
\hline 2 & $\begin{array}{l}\text { Iron - nickel- } \\
\text { chromium. }\end{array}$ & .074 & 0.0025 & 0.0003 & do & 41,500 \\
\hline $2 \mathrm{~A}$ & _.... do _.... & .074 & .0025 & .0003 & $\begin{array}{l}\text { Heated at } 500^{\circ} \mathrm{F} \\
\text { for } 5 \text { min after } \\
\text { machining. }\end{array}$ & 44,000 \\
\hline $2 \mathrm{~B}$ & $\ldots \mathrm{do}$ & .074 & .0025 & .0003 & $\begin{array}{l}\text { Tinned at } 500^{\circ} \mathrm{F} \\
\text { for } 5 \text { min after } \\
\text { machining. }\end{array}$ & 43,000 \\
\hline 3 & ..... do & .072 & .003 & .0003 & $\begin{array}{l}\text { Heated to } 500^{\circ} \mathrm{F} \\
\text { for } 5 \text { min before } \\
\text { machining. }\end{array}$ & 43,000 \\
\hline $3 \mathrm{~A}$ & ..... do & .072 & .003 & .0003 & $\begin{array}{l}\text { Heated to } 500^{\circ} \mathrm{F} \\
\text { for } 5 \mathrm{~min} \text {, ma- } \\
\text { chined, then } \\
\text { tinned at } 500^{\circ} \\
\text { F. }\end{array}$ & 44,000 \\
\hline 4 & .... do & .077 & .003 & .0006 & $\begin{array}{l}\text { Tinned at } 500^{\circ} \mathrm{F} \\
\text { for } 5 \text { min before } \\
\text { machining. }\end{array}$ & 38,500 \\
\hline 5 & ...... do_. & .073 & .005 & .0004 & "As deposited" . & 40,500 \\
\hline
\end{tabular}

"All plating was deposited with intermittent removal for "detreeing" except sheet 5, which was continuously deposited (no "detreeing").

TABLE 2. Results of flexure fatigue tests on bonded plates

\begin{tabular}{|c|c|c|c|c|}
\hline \multirow{2}{*}{ Plate } & \multicolumn{2}{|c|}{$\begin{array}{l}\text { Thickness of elec- } \\
\text { troformed layer }\end{array}$} & \multirow{2}{*}{ Bonding agent } & \multirow{2}{*}{$\begin{array}{c}\text { Fatigue } \\
\text { limit } \\
\left(10^{7}\right. \\
\text { cycles })\end{array}$} \\
\hline & Iron & Nickel & & \\
\hline 1 & $\begin{array}{l}\text { in. } \\
0.078\end{array}$ & $\begin{array}{l}\text { in. } \\
0.0028\end{array}$ & $\begin{array}{l}2 \text { brush coats of plastic adhe- } \\
\text { sive. }\end{array}$ & $\begin{array}{l}\text { lb/in.2 } \\
46,000\end{array}$ \\
\hline & .079 & .003 & $\begin{array}{l}1 \text { brush and } 1 \text { spray coat of } \\
\text { plastic adhesive. }\end{array}$ & 43,000 \\
\hline 3 & .074 & .003 & 50-50 tin-lead solder -- & 40,000 \\
\hline
\end{tabular}

The electroformed shells for the bonded plates were prepared in a manner essentially similar to that used for the electrolytic sheets described above. In every case they consisted of a layer each of iron and nickel of the respective thicknesses indicated in figure 2 . These composites were ground on the iron face with a Blanchard grinder, and this surface then was cleaned by brushing with lime, pumice, and water. Finally it was washed with a 10 -percent aqueous solution

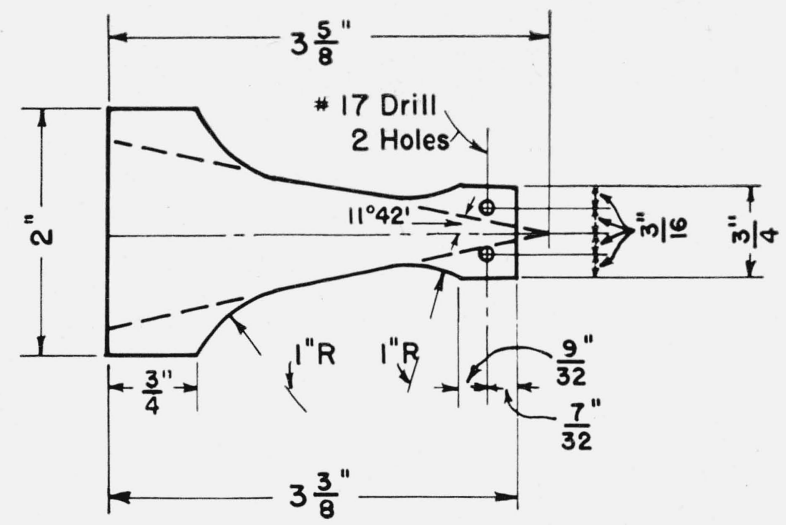

Figure 3. Design of specimen used for determining the flexural fatigue properties of electroformed sheets.

of hydrochloric acid. The bonding surfaces of the open hearth iron backs were similarly ground, cleaned, and treated with acid.

Soldering the electrolytic shell to the iron back was accomplished by fluxing the contacting iron surfaces with zinc chloride, sandwiching a 0.005 in.-thick sheet of 50-50 tin-lead solder between these surfaces, pressing them together at a temperature of $260^{\circ} \mathrm{C}\left(500^{\circ} \mathrm{F}\right)$ under a pressure of $80 \mathrm{lb} / \mathrm{in}^{2}$ in a press equipped with electrically heated plattens and cooling under pressure of 80 $\mathrm{lb} /$ in. $^{2}$ in a water-cooled press.

When the joints were made by adhesive cementing, the mating surfaces first were washed with an abrasive soap and water and then cleaned with steel wool. After thoroughly drying the surfaces, a coat of plastic adhesive was applied with a brush to each of them. Following a drying period of $30 \mathrm{~min}$, a second coat of adhesive was applied, in some cases by brushing and in others by spraying, which also was allowed to dry in air for $30 \mathrm{~min}$. These coatings then were dried at $85^{\circ} \mathrm{C}\left(185^{\circ} \mathrm{F}\right)$ for $25 \mathrm{~min}$, after which the coated surfaces were mated and pressed together under a stress of approximately $80 \mathrm{lb} /$ in. $^{2}$ at a temperature of $160^{\circ} \mathrm{C}\left(325^{\circ} \mathrm{F}\right)$ for $30 \mathrm{~min}$.

The plates bonded by these methods had a nickel face and an iron back. Surface metal was removed from the iron backs by grinding with a Blanchard surface grinder until the plates were approximately 0.2 in. thick. Specimens of the form and dimensions shown in figure 4 were cut from these plates. In all cases, the edges of the specimens within the gage length were polished with fine (3/0 emery) abrasive paper to remove surface irregularities in the same manner and for 


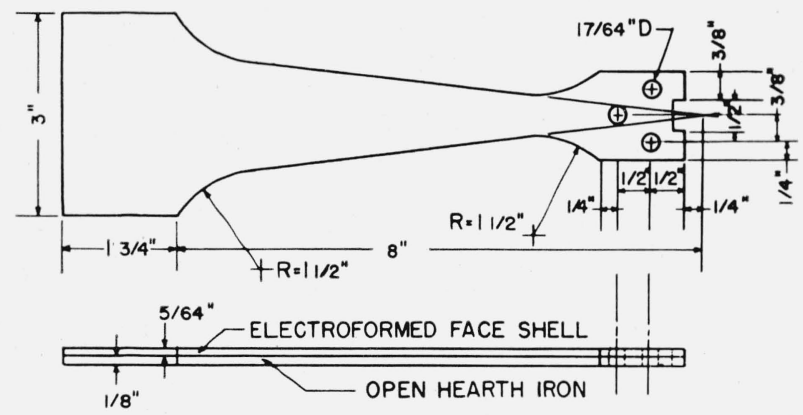

Figure 4. Design of specimen used for determining the flexural fatigue properties of composite plates of electroformed nickel-iron shells bonded to open hearth iron backs.

the same purposes as described for the electroformed sheet specimens.

\section{Method of Test}

The flexural fatigue tests were made on Krouse plate fatigue machines operating at 1,750 rpm. (fig. 5). The electroformed sheet and composite plate specimens in every case were adjusted in the machine so that the range of stress applied to the specimen face (nickel or chromium surfacesee table 1) was from zero to maximum tension and the back (iron surface) was in zero to maxi-

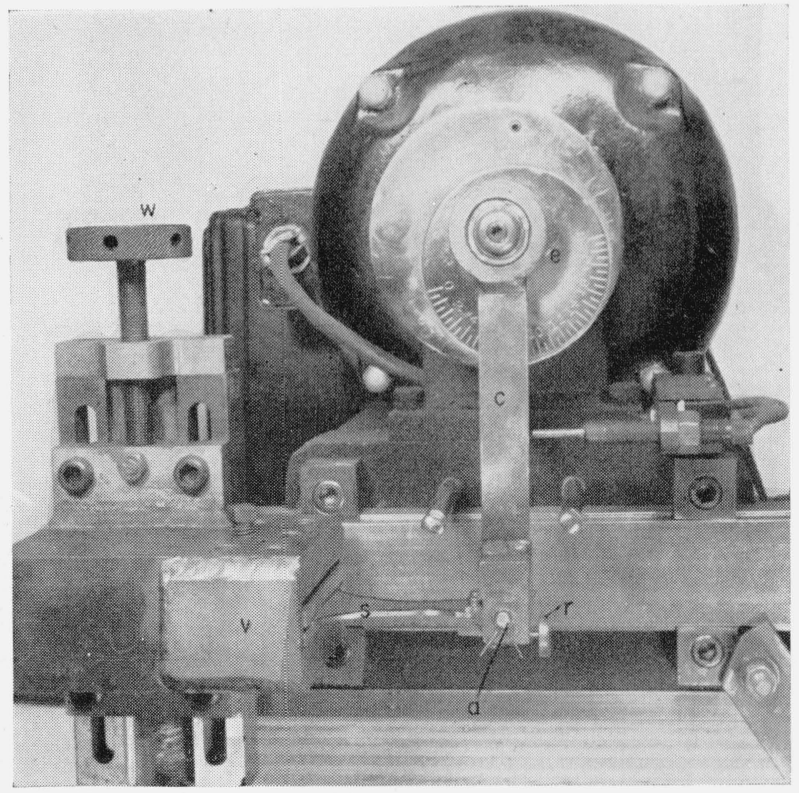

Figure 5. Machine used for making flexural fatigue tests showing manner in which specimen is supported.

$\mathrm{s}=$ specimen; $\mathrm{v}=$ vise for holding specimen in rigid position; $\mathrm{w}=$ serew for adjusting height of vise $\mathrm{v} ; \mathrm{c}=$ crank-arm for actuating specimen $\mathrm{s}$; $\mathrm{a}=$ connecting pin for attaching arm $\mathrm{e}$ to specimen $\mathrm{s}$; $\mathrm{e}=$ adjustable eccentric for varying throw of connecting arm $\mathrm{c} ; \mathrm{r}=$ reflecting mirror used for ascertaining specimen deflection in terms of stress as shown in figure 6. mum compression. This stress cycle was used to simulate that to which a printing plate is subjected on the press.

The specimens were deflected to produce the maximum flexural stress by adjusting the eccentric (fig. 5, e) in the usual manner ${ }^{6}$ except that the method used for measuring the deflection (fig. 6) was somewhat different from that generally employed with the Krouse flexure machine. Essentially it consisted of a flat mirror ( $r$, fig. 5 ), attached to the adapter securing the specimen to the crank arm, which reflected a horizontally collimated beam of light to a 12 -ft-long scale placed about $20 \mathrm{ft}$ from the mirror (fig. 6). This permitted the reproducibility of any desired maximum stress to within 1 percent.

Each testing machine was equipped with a microswitch, which was automatically operated to open the motor circuit and thus stop the machine when a test specimen ruptured completely. A counter attached to the machine recorded the number of flexural stress cycles to which a specimen was subjected during test. In the case of some of the plate specimens, particularly those bonded by soldering, the electrolytic shell and the bond frequently failed first, whereas the back remained intact. Under this condition the stress in the iron back was decreased below its fatigue limit, and

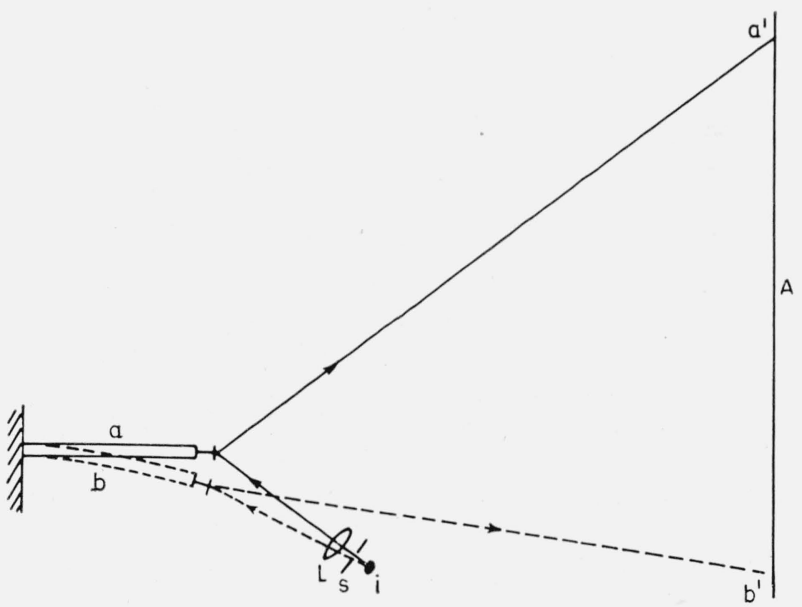

FiguRE 6. Diagrammatic sketch showing the manner of measuring the deflection of the flexural fatigue specimen when loaded.

The light beam from (I) passing through slit (S) and lens (L) is reflected by mirror to $\left(\mathrm{a}^{\prime}\right)$ on seale (A) when specimen is at zero stress position (a) and to $\left(b^{\prime}\right)$ when at maximum stress position (b). The freely suspended end of the specimen is then attached to the crank-arm (fig. 5) and deflections corresponding to zero stress $\left(\mathrm{a}^{\prime}\right)$ and maximum stress $\left(\mathrm{b}^{\prime}\right)$ are obtained by adjusting the eccentric arm (fig. 5)

${ }^{6}$ Fatigue tests, H. F. Moore, ASM Handbook, 119 (1948). 
the machine would run until stopped manually. Therefore, unless an operator was in constant attendance, a record of the number of cycles for failure of the shell was not obtained. In order to provide for this contingency, a special circuit comprising a relay in series with a number $38 \mathrm{~B}$ and $\mathrm{S}$ gage silk covered enamel copper wire secured with Duco cement to the upper surface of the specimen (fig. 7) was installed to interrupt the test when rupture of the shell occurred before complete failure of the back.

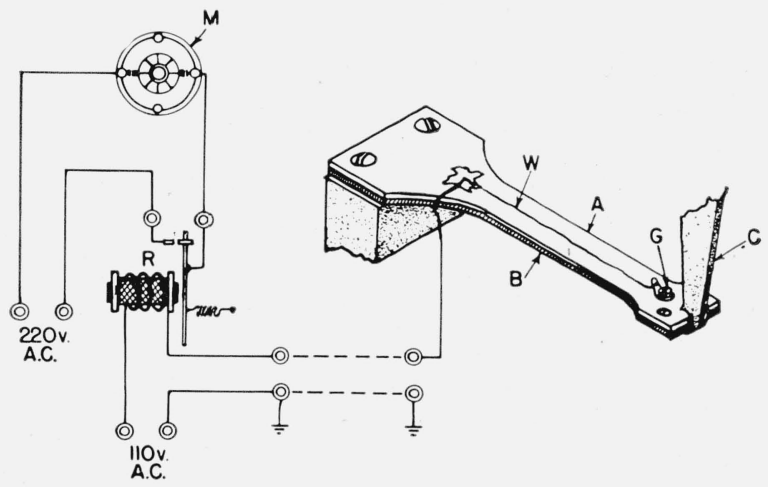

FIGURE 7. Schematic diagram of the relay system used to discontinue the flexural fatigue test when the electroformed nickel-iron layer $A$ (white section) failed while the fabricated iron backing $B$ (cross-hatched) remained intact.

When the electroformed layer A fractured, the copper wire W (grounded from $G$ through the machine) ruptured, opening the relay $R$ and stopping the machine.

In the present study the fatigue test was employed primarily as a means of obtaining an approximate relative measure of damage by flexing associated with the plating, thermal and bonding treatments employed. Because of this and the limited number of specimens available for test, the values selected for the fatigue limit were based on a stress, 500 to $1,000 \mathrm{lb} /$ in. $^{2}$ below the lowest stress resulting in failure, provided at least two runs of not less than 10 million cycles had been made at this stress.

\section{Results and Discussion}

The S-N (stress-cycle) curves for each of the electro-formed materials tested are shown in figures 8 to 12, inclusive. The fatigue limits indicated in these figures are listed in table 1 . It is apparent from a comparison of the curves in figures 8 and 9 that the fatigue properties of an iron-nickel composite sheet were affected adversely by the application of a thin (0.0003 in.) electro-

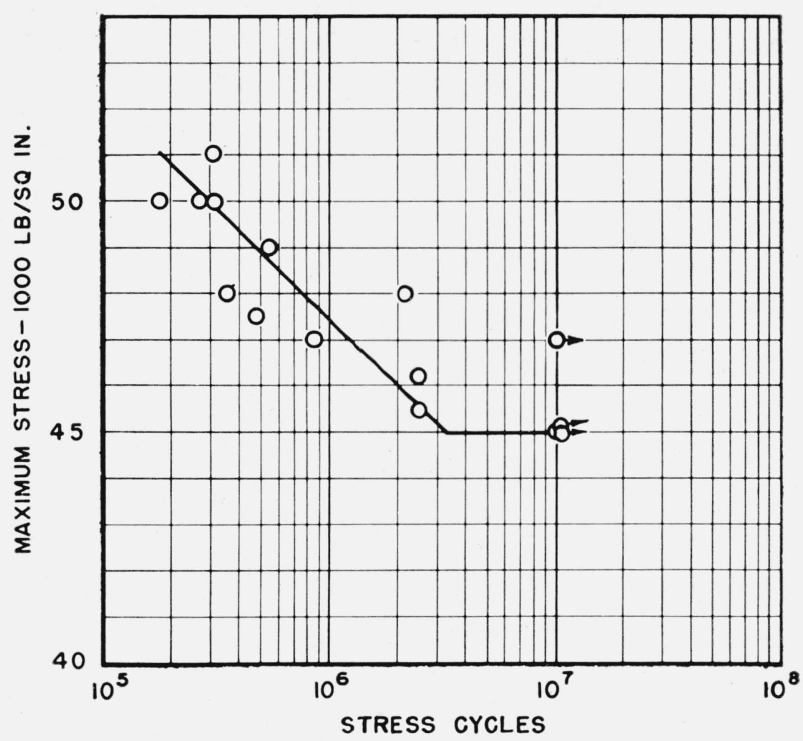

Figure 8. Stress-cycle $(S-N)$ graph based on results of flexural fatigue tests made on specimens of sheet No. 1 (table 1).

deposited coating of chromium (fig. 1, b). Hows ever, this influence of the chromium layer wasomewhat beneficially modified by thermal treatment (heated at $260^{\circ} \mathrm{C}\left(500^{\circ} \mathrm{F}\right)$ for $\left.5 \mathrm{~min}\right)$, (figs. 9 and 10). Maximum improvement appeared to be obtained when the chromium plated ironnickel sheet was heated $\left(260^{\circ} \mathrm{C}\right.$ for $\left.5 \mathrm{~min}\right)$ after machining. In the cases of the solder-coated

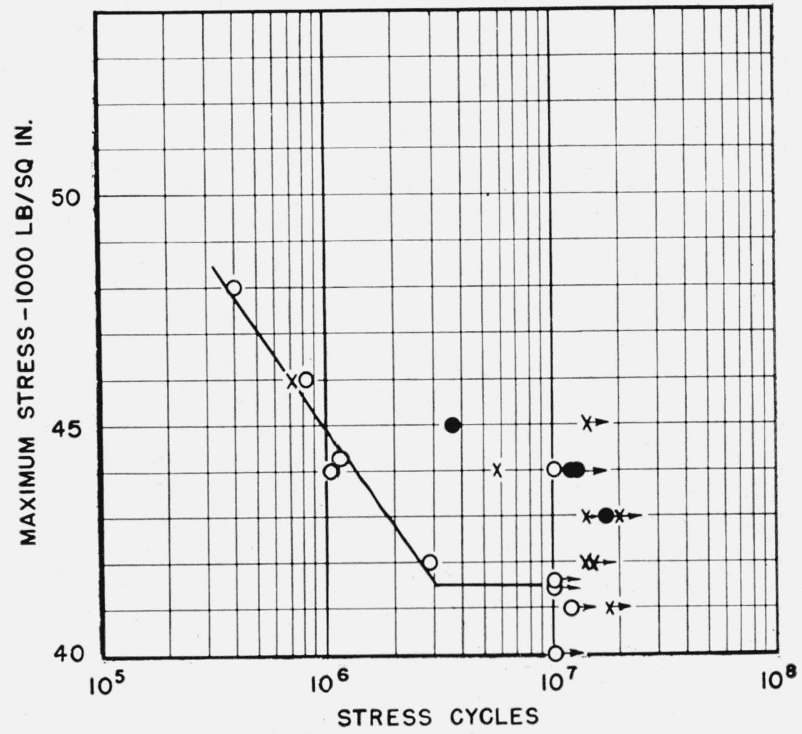

Figure 9. Stress-cycle $(S-N)$ graph based on results of flexural fatigue tests made on specimens of sheets No. 2 , $2 A$, and $2 B$ (table 1).

$\mathrm{O}$, as electroplated (sheet 2); X, tinned $5 \mathrm{~min}$ at $500^{\circ} \mathrm{F}$ after machining (sheet $2 \mathrm{~A}$ ); $\boldsymbol{\bullet}$, heated $5 \mathrm{~min}$ at $500^{\circ} \mathrm{F}$ after machining (sheet $2 \mathrm{~B}$ ). 
specimens, any deleterious effects that may have been imparted by the iron-tin compound formed at the iron-solder interface, apparently wereovershadowed by the improvement resulting from the thermal effects (figs. 9 and 10).

The results of the tests on the specimens machined from the electroformed sheet 4 of ironnickel-chromium after solder coating (fig. 1, d) at $260^{\circ} \mathrm{C}\left(500^{\circ} \mathrm{F}\right)$ (at temperature $5 \mathrm{~min}$ ) showed considerably lower fatigue properties (fig. 11) than any of the electroformed sheets tested. It is noteworthy that the fatigue properties were significantly higher for the specimens cut from sheets $2 \mathrm{~B}$ and $3 \mathrm{~A}$ (table 1 , also fig. 1, b, and c) having a 0.0003 -in. thickness of chromium plate than for those prepared from sheet 4 (table 1 and fig. 1, d) plated with a $0.0006 \cdot$ in. thickness of chromium. Recent work done at the National Bureau of Standards ${ }^{7}$ showed in certain cases that a plate thickness of $0.001 \mathrm{in}$. of chromium reduced the endurance properties of steel more than an appreciably thinner electrodeposit of this metal. This suggests that the lower fatigue limits (table 1) obtained on specimens of sheet 4 as compared with those machined from sheet 3 were attributable, at least in part, to the thicker deposit of chromium on sheet 4 .

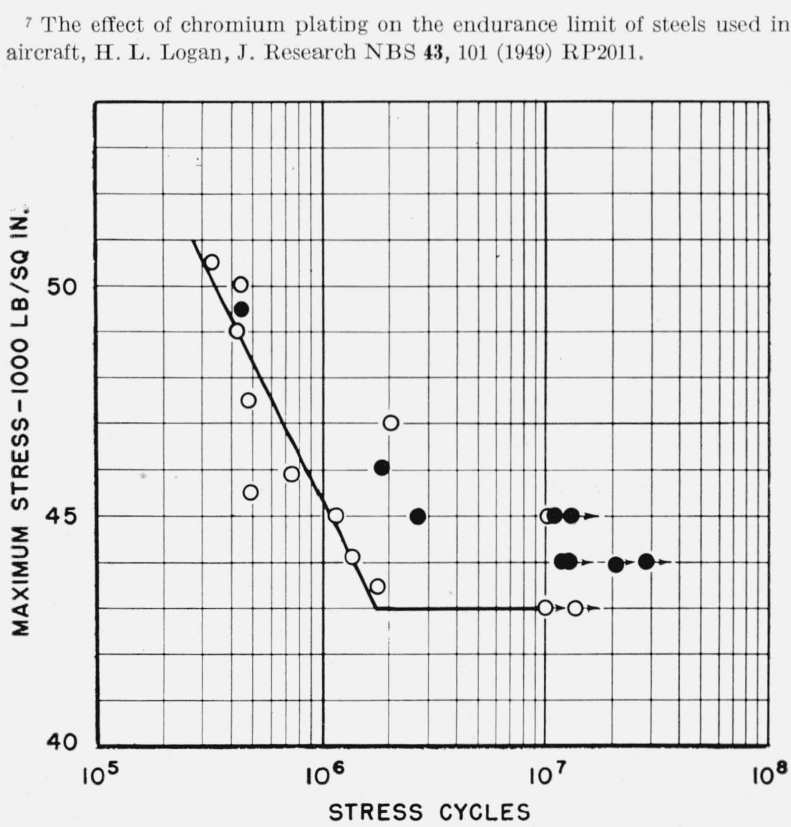

FiguRE 10.- Stress-cycle $(S-N)$ graph based on results of flexural fatigue tests made on specimens of sheets No. 3 and $3 A$ (table 1).

$\bigcirc$, Heated for $5 \mathrm{~min}$ at $500^{\circ} \mathrm{F}$ before machining (sheet 3 ); $5 \mathrm{~min}$ at $500^{\circ} \mathrm{F}$, machined and then tinned for $5 \mathrm{~min}$ at $500^{\circ} \mathrm{F}$. (sheet $3 \mathrm{~A}$ ).

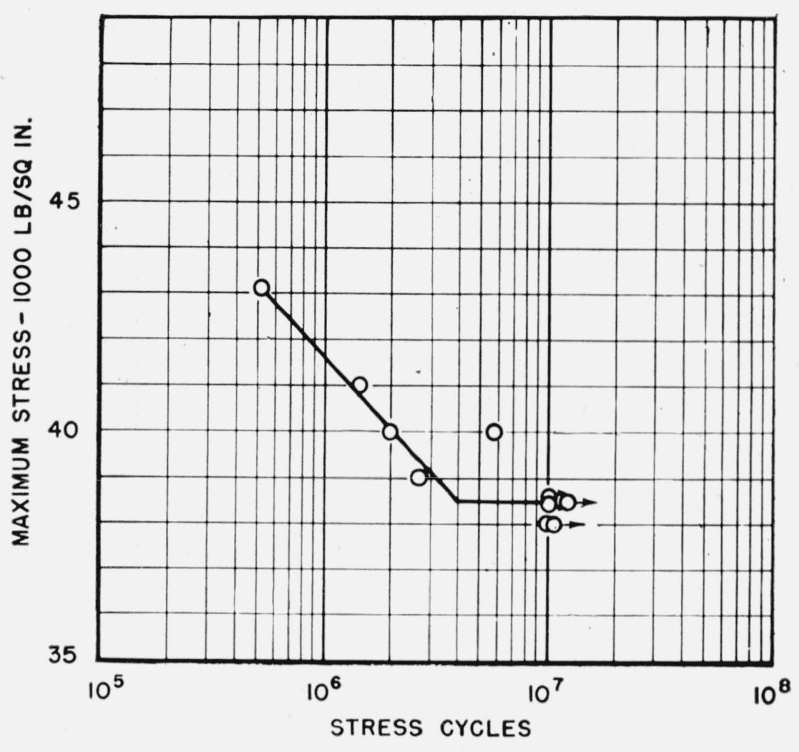

Figure 11. Stress-cycle $(S-N)$ graph based on the results of flexural fatigue tests made on specimens of sheet No. 4 (table 1).

The fatigue limit of sheet 5 (fig. 1, e) formed by continuous electrodepositing (no detreeing) was somewhat lower than for material electroformed similarly (sheet 2, table 1, fig. 1, b) except for intermittent removal from the plating bath for detreeing. However, the adverse effect on the fatigue limit by thicker deposits of chromium previously discussed is considered to have been a greater influencing factor than the omission of the detreeing treatment.

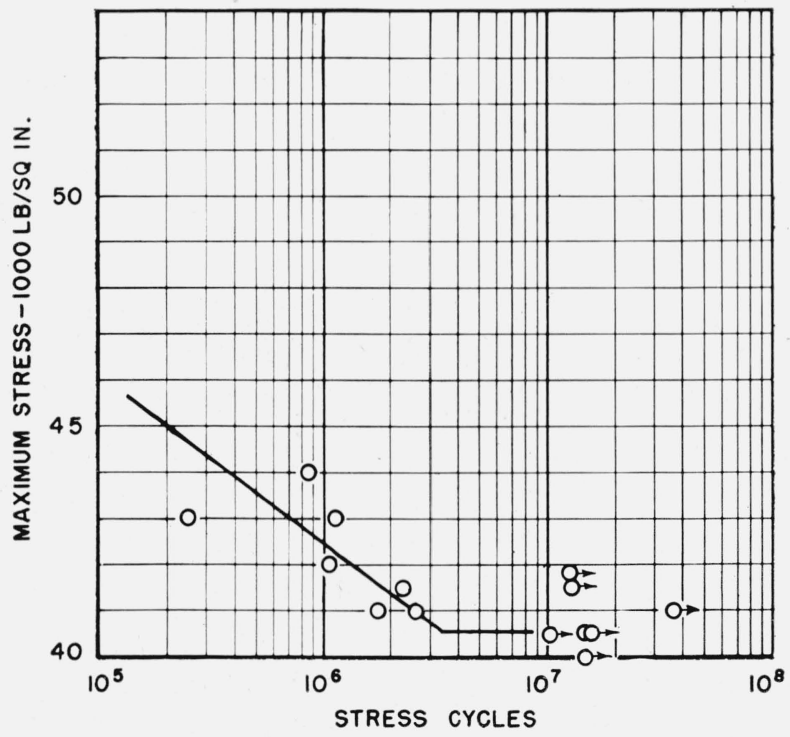

Figure 12. Stress-cycle $(S-N)$ graph based on the results of flexural fatigue tests made on specimens of sheet No. 5 (table 1). 


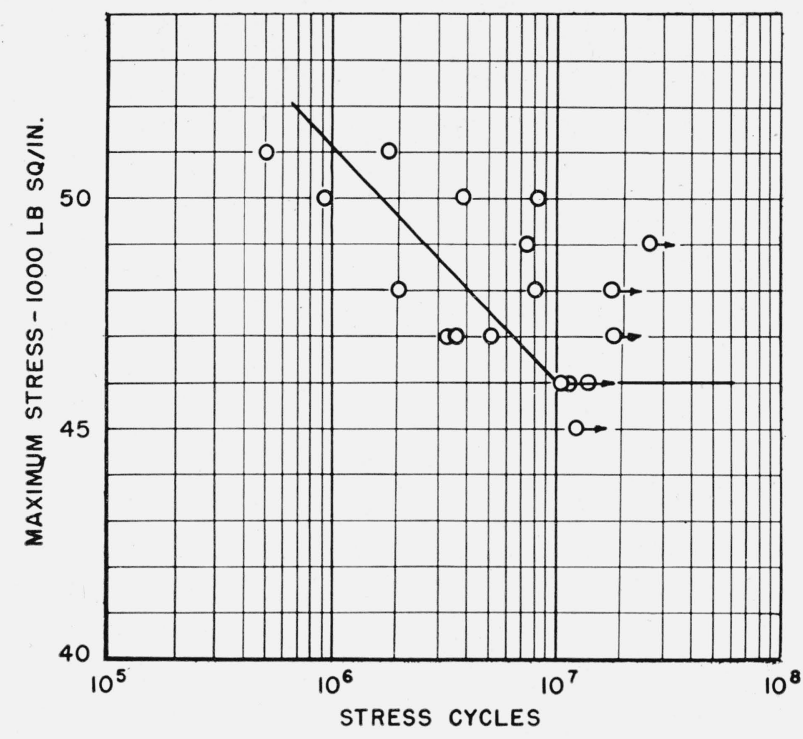

FIGURE 13. Stress-cycle (S-N) graph based on the results of flexural fatigue tests made on specimens of printing plate composed of an electroformed shell of a layer each of iron and nickel ( $f$ g $g$. 2) bonded to a backing of open hearth iron with two brushed coats of plastic adhesive.

The results of the tests on specimens prepared from plates composed of electroformed sheets of iron-nickel bonded to open hearth iron backs are shown in figures 13 to 15 , inclusive. It will be noted that the solder-bonded plate (fig. 15) had

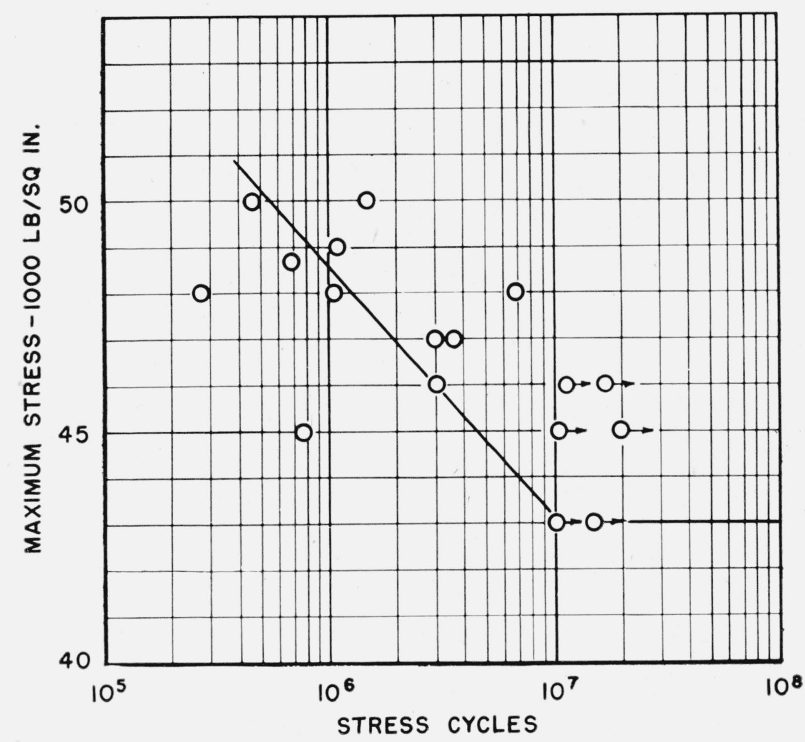

FIgURE 14. Stress-cycle $(S-N)$ graph based on the results of flexural fatigue tests made on specimens of printing plate composed of an eelctroformed shell of a layer each of iron and nickel (fig. 2) bonded to a backing of open hearth iron with first a brushed coat and then a sprayed coat of plastic adhesive. an appreciably lower fatigue limit than either of the composites bonded with the plastic adhesive (figs. 13 and 14). Furthermore, the specimens that were bonded with two brushed coats of the adhesive showed superior fatigue properties to those joined after applying first a brushed coat and then one by spraying. In nearly every case the failure of the soldered specimens was accompanied by a failure of the bond (fig. 16, a). The plastic bonded specimens rarely showed any indication of this type of failure, complete rupture occurring without separation of the component electroformed and fabricated iron layers as shown in figure $16, \mathrm{~b}$.

A factor that in the greatest measure may be responsible for the adherence of the layers bonded with the plastic and the separation of those soldered is the degree of continuity of the bond. Thus, in every case examined the plastic bond was continuous (fig. 17, b) and in the case of separated soldered joints, there was evidence of discontinuities or porosity (fig. 17, a) in the bond layer. Another factor that may contribute to this result is the fact that the modulus of elasticity of the iron-tin compound at the interface of the solder and iron is higher than that of the plastic adhesive.

During the flexing action of the specimens, there was an appreciable stress applied to the bond layer. If the bond layer is of a porous nature, such as illustrated in figure 17 , a, then its fatigue

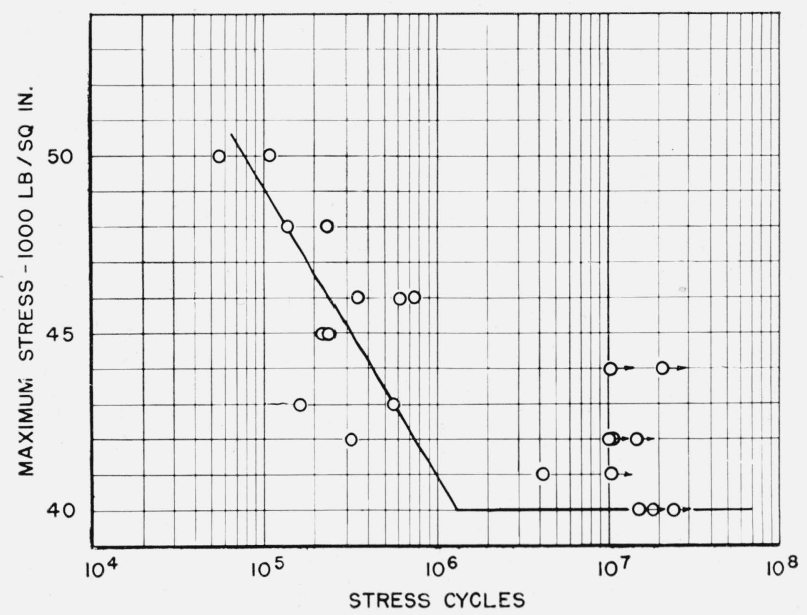

Figure 15. Stress-cycle $(S-N)$ graph based on the results of flexural fatigue tests made on specimens of printing plate composed of an electroformed shell of a layer each of iron and nickel (fig. 2) bonded to a backing of open hearth iron with 50-50 tin-lead solder. 


\section{OPEN HEARTH IRON BACK}

a

\section{ELECTROFORMED SHEET}

OPEN HEARTH IRON BACK

FiguRE 16. Side view of flexural fatigue plate specimens showing the general manner in which failure occurred in the solder and plastic bonded plates respectively.

a, Solder bonded specimen showing separation of the electroformed shell (upper portion) from the open hearth iron base; b, Plastic bonded specimen showing adherence of the electroformed shell to the iron base after complete fracture of the specimen.
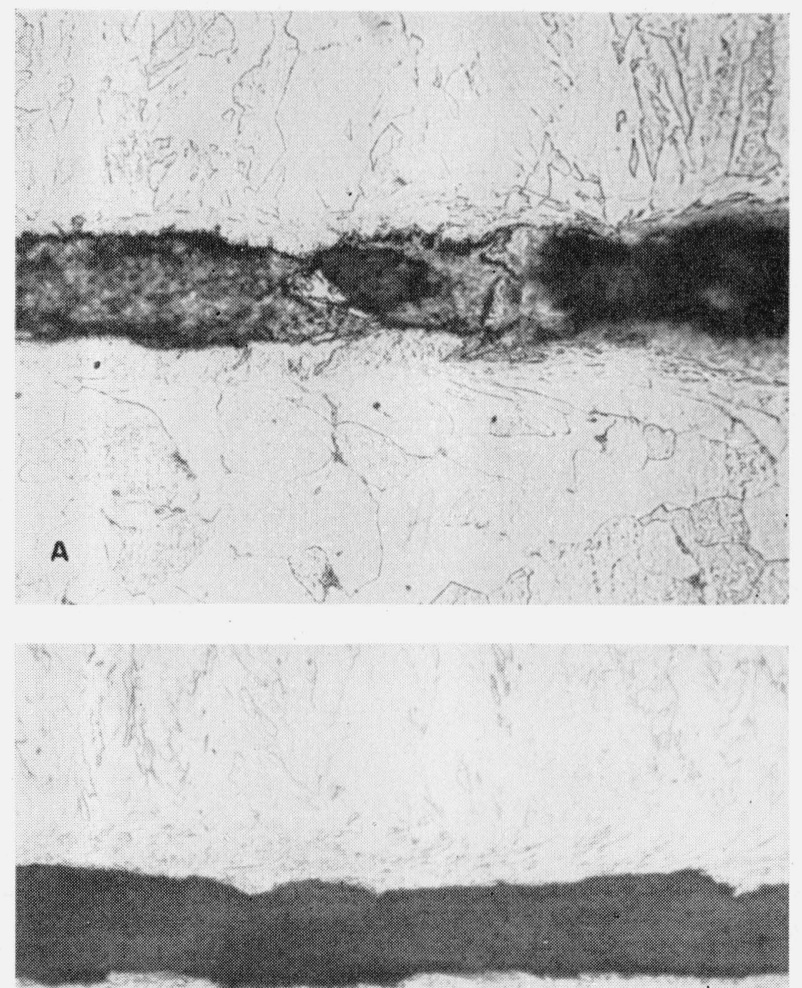

B

FIGURE 17. Characteristic appearance of the bond layer between electroformed shell and open hearth iron back comprising the printing plate tested.

Etched with 1 percent nital, $\mathrm{x} 250$; a, Solder (50-50 tin-lead) showing discontinuity and porosity (black areas); b, plastic adhesive. strength might be sufficiently low to permit rupture during flexing with consequent separation of the two constituent layers. Despite this separation the layers remained firmly cemented together at their ends. This permitted a slight elongation and bowing of the electroformed layer (fig. 18), thus imposing a compressive stress on its bottom surface and tensile stress on its upper surface when the specimen was in the initially set zero stress position. As the specimen passed through a complete flexing cycle, the bottom face of the electroformed layer being above the center plane of the specimen parallel to its broad face (fig. 18) was subjected to a reversal of stress from compression to tension to compression. This suggests that since the maximum tensile stress imposed on the bottom face of the electroformed layer was approximately the same before and after the solder layer failed, the stress range for this bottom face increased after bond failure. This factor, coupled with stress raisers on the bottom face associated with the voids in the solder layer (fig. 17, a) and the corrosion effects of the excess soldering flux residing in the voids, may have caused fatigue failure of the electroformed layer.

Although the bonded printing plates commonly are chromium-plated on the nickel face, none of the bonded plates tested were thus plated. The results obtained on the electrolytic shells (figs. 8 to 12 , inclusive) clearly indicate that the endurance properties of chromium-plated bonded plates would be somewhat lower than those shown for the bonded specimens tested (figs. 13, 14, and 15). However, on the basis of available service data, it 
is not expected that the chromium plate would have altered the relative results as influenced by the type and method of bond employed.

\section{Summary}

A laboratory study was made to ascertain the flexural fatigue properties of electroformed ironnickel and iron-nickel-chromium composite sheets and of plates composed of electroformed iron-
3. The application by brushing of the two coats of plastic adhesive to the mating surfaces of the composite layers of the plate resulted in a higher fatigue limit than the one brush and one spray coat procedure.

4. In nearly all cases, the solder bond failed either just prior to or simultaneously with the failure of the electroformed layer; the fabricated iron back remained intact under these circumstances. The number of plastic bond failures was

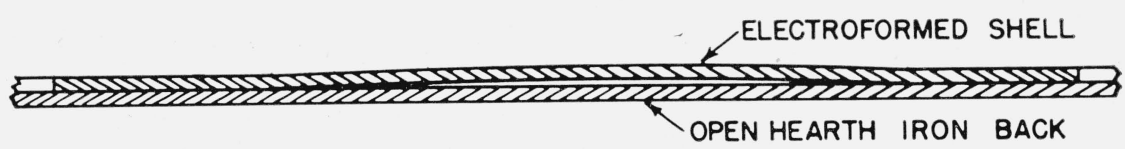

FIGURE 18. Schematic diagram indicating the bowing effect probably produced in the electroformed shell due to elongation of the shell during flexing after failure of the bond but before rupture of either the electroformed shell or the iron back.

nickel sheets bonded to open hearth iron. The electroformed sheets in every case consisted of one layer of each of the constituent metals. The bonding agents used in preparing the plates were 50-50 tin-lead solder, and a plastic adhesive applied in some cases as two brushed coats and in others as one brushed and one sprayed coat respectively to each of the two mating surfaces. On the basis of the results of this investigation, it is concluded that:

1. The fatigue limit of an iron-nickel composite is adversely affected by the application of a thin electrodeposited coating of chromium. Heating such tri-layer composites at $260^{\circ} \mathrm{C}\left(500^{\circ} \mathrm{F}\right)$ caused some increase of its fatigue limit. The most pronounced improvement resulted from heating at this temperature after machining.

2. The fatigue limits of the plates bonded with the plastic adhesive were significantly higher than those of the plates joined by soldering. negligible; in nearly all cases the iron layer remained secured to the electroformed layer and they failed as a unit.

5. The lower fatigue strength of the solder bonded specimens was attributed to the brittle iron-tin layer at the interface of the solder and iron, porosity or discontinuity of the solder layer, and corrosion caused by residual flux residing in the voids of the solder.

6. The results of this study are consistent with the service data of printing plates compiled at the Bureau of Engraving and Printing over a period of years in that the average life of the plastic bonded plates is considerably greater than the average life of plates whose component layers were joined by soldering.

Washington, May 27, 1949. 